\title{
Особенности образа современного русского интеллигента на примере романа Алексея Варламова Затонувший ковчег (1997)
}

\author{
Singularity of the image of the contemporary \\ Russian intellectual through the example of the novel \\ of Aleksey Varlamov The Sunken Ark (1997)
}

\begin{abstract}
The article focuses on the image of the modern Russian intellectual, depicted in the artistic text of Aleksey Varlamov, the Sunken Ark. Understanding the phenomenon of the Russian intelligentsia in the analysed literary work is associated with the problem of the opposition of reason and faith in the process of the personality formation of the modern intellectual. The analysis carried out in the text allows not only to trace and better understand the social processes of the crisis period in Russia, but also to notice their enormous impact on the consciousness of the main hero-intellectual Ilya Petrovich. The use of the methodology of historical and literary research in the work is adequate to the problems posed. The novel under analysis, as a kind of warning, has a deep philosophical undertone that touches upon the problems of faith, unbelief, freedom of the individual and the pursuit of moral perfection. Varlamov's intellectual, as a typical "hero of our time", regardless of his weakness, defenselessness and internal rupture, seems to be most needed in life.
\end{abstract}

Keywords: image of the modern Russian intellectual, Aleksey Varlamov, Sunken Ark, faith and reason

Natalia Królikiewicz, Uniwersytet im. Adama Mickiewicza w Poznaniu, Poznań - Polska, n.krolikiewicz@tlen.pl, ORCID ID: https://orcid.org/0000-0002-3083-8774

Проза известного писателя Алексея Николаевича Варламова, продолжающая традиции русского классического реализма, обращена не только к извечным загадкам человеческого бытия, но и к насущным темам современности. Творчество названного художника, будучи значительным литературным явлением, выражает также важнейшие тенденции художественных процессов в русской прозе конца XX - начала XXI веков. Имеется в виду не только выделение своеобразного творческого метода писателя „символический реализм” (Mineralov 244), „леонидоандреевский реализм” 
(Slaveckij 110), но и создание образа современного интеллигента - „нового лишнего” (Kurbatov 3), „пассивного рефлексирующего героя” (Remizova 8). Такой тип „героя нашего времени” с неопределенными идейно-нравственными установками и отношениями характерен для культурной ситуации рубежа веков и обнаруживается в творчестве не только Варламова, но и других писателей: Владимира Березина, Антона Уткина, Андрея Дмитриева и др. (Sčastlivceva 13).

Целью настоящей работы является исследование образа современного русского героя-интеллигента в романе Варламова Затонувший ковчег (1997). В связи с данной целью важными представляются следующие задачи: осмыслить феномен русской интеллигенции, проанализировать проблему формирования личности современного интеллигента и выявить в данном процессе наличие противоположных жизненных сил - разума и веры, воздействующих на нравственную позицию героя-интеллигента в художественном пространстве произведения. Теоретической базой для настоящей статьи послужили работы Михаила Бахтина (Bahtin), Дмитрия Лихачева (Lihačev), Юрия Лотмана (Lotman), Галины Нефагиной (Nefagina), Валентина Курбатова (Kurbatov), Юлии Счастливцевой (Sčastlivceva), и других ученых.

Прежде чем перейти к анализу литературного произведения, целесообразно кратко напомнить о специфическом феномене русской интеллигенции, являющимся ключевой составляющей в поисках национальной и культурной идентичности России. Сложность и расплывчатость самого понятия „интеллигенция” являются причиной бурных дискуссий в научной среде. Интеллигенцию „называют «самым таинственным персонажем российской истории», который окружен «ореолом противоречивых мифов, гипотез, контроверз и плохо совместимых фактов»" (Sokolov 3).

Латинское intelligens переводится как умный, понимающий, мыслящий и обозначает людей, профессионально занимающихся умственным трудом. Впервые термин „интеллигенция” был введен писателем Петром Дмитриевичем Боборыкиным (с 60-х годов XIX века). Подразумевались под этим словом творческие группы людей умственного труда, ориентированные на исполнение гражданского и нравственного долга перед народом и на приобщение народа к достижениям мировой культуры.

Следует заметить, что при изучении проблемы интеллигенции некоторые ученые рассматривают русскую интеллигенцию как феномен, аналогичный западным интеллектуалам, в то время как другие - используют полностью противоположную по смыслу трактовку. По мнению филолога Юрия Михайловича Лотмана, синтетически соединившего вышепредставленные крайние подходы, „для российской интеллигенции характерен напряженный 
самоанализ и поиск собственной идентичности” (Lotman 132). Кроме того, ученый подчеркивает присущую интеллигенту установку на понимание Другого, на диалог (Lotman 139). Такая обращенность к Другому корреспондирует с трудами известного мыслителя Михаила Михайловича Бахтина: „[...] поскольку человек для себя никогда не является целостным и завершенным, то целостно познать его может только Другой. Другой может познать меня, а я могу познать Другого" (Zinov'eva, электронный ресурс).

Проблеме интеллигенции посвятил внимание Дмитрий Сергеевич Лихачев, придерживающийся мнения о том, что

\begin{abstract}
многие думают: интеллигентный человек - это тот, который много читал, получил хорошее образование (и даже по преимуществу гуманитарное), много путешествовал, знает несколько языков. А между тем можно иметь все это и быть неинтеллигентным, и можно ничем этим не обладать в большой степени, а быть все-таки внутренне интеллигентным человеком. Интеллигентность не только в знаниях, а в способностях к пониманию другого (Lihačev 3).
\end{abstract}

Итак, интеллигентность (как производное от интеллигенции) трактуется ученым как умение вести себя в обществе, понимать и оценивать по достоинству другого человека и окружающий мир. Лихачев определял интеллигенцию как явление уникальное, присущее только русской культуре. Свобода для интеллигента - это нравственная категория. Не свободен интеллигентный человек только от своей совести и своей мысли (Lihačev 5). Coвесть в представлении Лихачева - ,это рулевой его свободы, она заботится о том, чтобы свобода не превращалась в произвол, но указывала человеку его настоящую дорогу в запутанных обстоятельствах жизни” (Lihačev 5).

Таким образом, можно сделать вывод, что феномену „русской интеллигенции" присущи общие и типичные черты: высокая нравственная ответственность, большая внутренняя культура, активная общественная позиция, ориентация на служение народу (однако в постсоветскую эпоху интеллигенция в целом не вписалась в экономические и культурно-политические условия), идея жертвенности (связанная с проблемой свободы), служения добру, напряженный самоанализ и поиск собственной идентичности.

Анализируемое произведение, опубликованное в журнале „Октябрь” в 1997 году, составляет часть (вместе с романами Лох и Купол) „некой трилогии 90-х о русской жизни, о ее вирусах, уязвимых местах" (Varlamov 1997: 69). Пораженное „вирусами” национальное сознание - это одна из ключевых тем творчества Варламова (в Лохе - апокалиптицизм, в Затонувшем ковчеге - сектантство, в Куполе - утопизм) (Fedorova 8, электронный ресурс). Общность названных романов обнаруживается не только в тематическом и жанрово-стилевом единстве, но и в сходстве идейно-философского контекста, а также в структуре образа главных героев. 
В рамках данной статьи мы вынуждены ограничиться анализом только Затонувшего ковчега, принадлежащего к жанру социально-психологического романа. Представляя широкую панораму российской жизни, эсхатологических и апокалиптических настроений на рубеже XX-XXI веков, автор в центр внимания ставит проблему личности и исследование кризисного сознания современного человека, живущего в эпоху смены культурных парадигм.

Следует дополнить, что Варламов замечает существенную разницу в понимании идеи Апокалипсиса в культуре периодов начала и конца XX века. В начале века крайне важным было рождение нового мира и нового человека, а под конец столетия - смерть этого мира и этого человека (Varlamov 1997: 70).

Очередным после Апокалипсиса вопросом является сектантство, именуемое писателем „вирусом стадности”, поразившим мир на пороге XXI века. О проблеме сектантства рассуждает один их героев Затонувщего ковчега, академик Виктор Владимирович Рогов:

Подлинная же беда России - ее сектантство [...] Секта декабристов и народников, хлыстов и духоборов, большевиков и диссидентов, секта „новых русских” и Божественного Искупителя - как по заколдованному кругу мчимся, и снова спотыкаемся, и вниз скатываемся. Есть что-то завораживающее в этих учениях, и вовлекаются в него самые чистые души, а над ними стоят проходимцы и чужой чистотой пользуются (Varlamov, электронный ресурс).

Герой (близкий автору романа) видит во множестве сект, политических и общественных движений специфические составляющие: стремление переделать мир рациональным путем, желание насильственно осчастливить людей, оправдание любых средств ради осуществления цели.

Необходимо напомнить, что после распада Советского Союза (на фоне развала экономики и различных преступлений) в России развиваются новые религиозные движения, которые „являются одним из ярких проявлений размытого парарелигиозного сознания россиян" (Lunkin, электронный ресурс). Сторонников новых религиозных движений насчитывается свыше 90\% населения страны, „поскольку большинство граждан подвержено фобиям, надеждам, любопытству к чему-то оккультному, стереотипам, связанным с астрологией, загробной жизнью, астральным миром, реинкарнацией и т. д." (Lunkin, электронный ресурс). Интерес к новым мифологиям, новоиспеченным пророкам, обещающим легкий путь к спасению, обнаруживает, как можно предполагать, отсутствие морального стержня, тот духовный вакуум, который образовался вследствие крушения коммунистической идеологии. Отсутствие 
авторитета и определенные дезинтеграционные процессы, происходившие в начале 1990 годов в Русской Православной Церкви (Przebinda), повлияли на то, что в указанное время на территории России действует огромное количество сект: „Белое братство”, „Богородицкий центр”, „Свидетели Иеговы”, „Церковь Виссариона” (или „Церковь Последнего Завета”). Черты последней из названных были использованы Варламовым в художественном пространстве романа. Секты, действительно, не являются чем-то новым, но опасность заключается в том, что в XX веке у них появилась возможность использования современных психологических наработок, с помощью которых можно психически воздействовать на сознание и манипулировать личностью, что приводит к потере внутренней свободы человека и еще большему духовному „закабалению” (порабощению) человеческой личности. Так, тема сектантства в более широком понимании сопряжена в произведении с проблемой духовного рабства человечества в конце XX века.

Повествование романа сводится к представлению жизни и гибели секты скопцов и небольшой деревни старообрядцев-отшельников. События выстраиваются в двух планах: в городе и провинции (о значении данной антитезы речь пойдет ниже). В Петербурге (Ленинграде) Борис Филиппович Люппо (в переводе с латинского „оборотень”, „волк в овечьей шкуре”) скопец-насильник, который в своё время изнасиловал несовершеннолетнюю и был оскоплен ее разгневанным отчимом, основал „Церковь Нового Завета". Одновременно в глухом уголке Севера находится староверческий скит Бухара, возглавляемый старцем Вассианом, в действительности оказавшимся интеллигентом-атеистом и бывшим советским историком Василием Васильевичем Кудиновым.

Нельзя не обратить внимания на название романа, перекликающееся с библейским мифом о всемирном потопе. Иносказательно в данном романе-притче представлен образ ковчега посредством Бухары - деревни, в которой еще с допетровских времен жили старообрядцы, стремившиеся уберечь свою истинную веру от современного мира с его пороками. Таким образом, социально-психологический план изображения действительности накладывается в романе на мифологический, связанный с христианским мировидением, что характерно для всего творчества писателя и свидетельствует о глубине его художественного взгляда.

Реализуя одну из основных задач данного исследования следует обратиться к образу главного героя романа Илье Петровичу. Приехавший добровольно в северный поселок „Сорок второй” молодой выпускник московского пединститута становится местным Ломоносовым, целиком возглавляя обучение в школе. Школьного директора дети обожают: 
Несмотря на грозную внешность, они чувствовали в нем необыкновенную доброту. К тому же знал он так много интересного и так здорово умел об этом рассказывать, что самые отпетые лентяи и хулиганы на его уроках смиренно сидели, слушая поразительные истории о великих открытиях, далеких землях, полетах в космос, роботах, компьютерах, освоении Севера и прочих достижениях постаревшего человечества (Varlamov, электронный ресурс).

Необходимо заметить, что и имя Ильи Петровича (Илья в переводе с др.евр. означает „крепость Господня”, а Петр с греч. - „камень”), и внешность (,здоровый мужик, которому впору было одному на медведя ходить”) обращают на себя внимание:

Директору было чуть больше тридцати, но выглядел он старше своих лет, быть может, потому что одиноко и нелюдимо жил на казенной квартире при школе. Широкоплечий, рослый, но как-то неладно скроенный, он внешне напоминал скульптуру (Varlamov, электронный ресурс).

В образе директора проявляются черты героев фольклора, улавливается связь с русской землей, ее богатырями (Ильей Муромцем) (Sčastlivceva 17). Образ Ильи Петровича представляет собой тип правдоискателя, традиционный для русской культуры и русской интеллигенции. В процессе становления личности героя-интеллигента Варламов изображает две противоположные жизненные силы, определяющие нравственный выбор человека, с одной стороны, безусловная вера в силу человеческого разума, с другой, - необходимость обрести духовную опору в религии. Причем процесс преодоления бытийной неопределенности показан в художественном тексте с различными нравственными испытаниями, заблуждениями и моментами осознания истины. Валентин Курбатов вполне точно прокомментировал кризис разумного и логического познания действительности, последствия которого отражены в романном пространстве: „Роман стал прекрасным документом растерянного мечущегося времени, которое и ищет «просторы» веры, и не может пересилить в себе настойчивого разума" (Kurbatov 4).

Пытаясь разобраться в жизни, „найти себя”, Илья Петрович, как можно предполагать, проделал свой путь из шумного столичного города в поселок „Сорок второй”. Русский север, будучи духовным центром притяжения для раскольников, сомневающихся, „сбившихся” с пути людей, видится герою неким убежищем от безнравственной современности, которую герой не принимает. Таким образом, в художественном пространстве романа выявляется ранее указанная антитеза: город как символ наступающего апокалипсиса и заброшенная таежная деревня как спасительный ковчег в современном, погрязшем во лжи и пороках мире. Однако лишенный духовной опоры просветитель Илья Петрович в северной глубинке не находит желанного спо- 
койствия. Более того, в ходе повествования северная столица и таежный скит оказываются своеобразными двойниками (о чем подробнее ниже).

Главный герой романа, Илья Петрович, интеллигент с атеистическими воззрениями отчаянно старается вести борьбу с антинаучными, суеверными взглядами бухарян, собираясь „спасти несколько десятков детишек, которые вместо того, чтобы слушать про Джордано Бруно, Галилея, Коперника, Ломоносова и Эйнштейна, проводят дни и ночи в тупых молитвах" (Varlamov, электронный ресурс). Однако все попытки школьного директора „с наскоку взять сектантскую цитадель и доказать упрямцам, что Бога нет, а их Бога нет вдвойне, оказались безрезультатными" (Varlamov, электронный ресурс). Осознавая бессмысленность своих действий, учитель начинает частенько выпивать (чем раньше отличался от односельчан), опускается и становится похожим на всех остальных жителей поселка.

Следует подчеркнуть, что внутренний мир варламовских героев раскрывается в некой знаковой, жизненно важной для персонажа ситуации (рождение, зрелость, смерть и др.) (Sčastlivceva 5). В анализируемом романном пространстве такой „пограничной” ситуацией, прерывающей привычные условия жизни, возможно, станет не только достижение личностной зрелости Ильи Петровича, но и встреча с его ученицей Машей, являющейся воплощением чистоты и истины для главного героя. Именно молодой директор спас и вынес из леса бесчувственную Машу Цыганову, пострадавшую от удара молнии:

Хотя от красавицы сосны, под которой пряталась от грозы Маша, остался один обугленный ствол и мох вокруг не рос еще очень долго, а земля почему-то выглядела как будто вскопанной, отроковица была цела и невредима (Varlamov, электронный ресурс).

Чудесное спасение девочки будет связано с тем, что под сосной, в которую ударила молния, откроют ковчег с мощами жившей в начале века и таинственно исчезнувшей „травницы Евстолии”, местночтимой святой. После такой „защиты” девочку стали почитать в Бухаре за Деву Марию. Чтобы спастись самому и спасти невинную и чистую Машу, в которую неудачливо влюблен учитель, Илья Петрович приводит отроковицу в скит. Несмотря на все тяжелые испытания Маша сохранила чистоту и независимость от того грязного мира, в котором жила, оставаясь самой собой.

Такая проверка литературного персонажа может корреспондировать с $u c$ пытанием любовью „лишнего героя” как известного литературного приема, характерного для литературы XIX века и подчеркивающего значительную роль женщины для становления личности мужчины. Можно добавить, что в образе Ильи Петровича узнаваемы и тематические признаки ,лишнего чело- 
века" (бессемейный, несчастный в любви, интеллектуально развит, талантлив, но полон противоречий), свидетельствующего о кризисе в обществе.

Можно также предположить, что встреча с Машей могла стать причиной осознания героем неслучайности всего происходящего и различения знаков Божьей воли в его земной судьбе. Так, и Илья Петрович, и скульптор Колдаев, познакомившийся в Петербурге с Машей, куда та сбежала после смерти матери и отказа идти в скит к старообрядцам, начинают поиски смысла жизни, находя его в приобщении к вере и Церкви. „Стремление примирить разум с верой, знание с моралью заставляет учителя обратиться за помощью в староверческую общину Бухару” (Sčastlivceva 131).

Интересно заметить, что этапы духовного становления, попытка выхода „новых лишних” героев к метафизическим глубинам бытия сопровождается в сознании героев психическими деформациями и расстройствами: состояние на грани нервного истощения, в котором пребывает Колдаев, болезнь Ильи Петровича. Такое полуосознанное бытие в романах Варламова, возможно, указывает на отказ от „запрограммированного” жизненного сценария.

Илью Петровича, после отъезда возлюбленной Маши, стала преследовать тоска, и он все чаще поддавался присущей ему рефлексии, чувствуя, как начинает тяготиться своей свободой. Потеряв веру в науку и людей, главный герой размышляет о том, что „нет ничего твердого и основательного в этом мире - ложью окажется то, что считалось долгое время правдой” (Varlamov, электронный ресурс). Постоянная рефлексия приводит Илью к убеждению, что только Бухара защищена от непрочного и фальшивого мира, что „нет в ней убийств и воровства, нет богатых и бедных, счастливых и несчастливых" (Varlamov, электронный ресурс). Правда, нет там свободы, да и скит, по сути, напоминает лагерь, ,а только кому она нужна, свобода эта - свобода пить или не пить, убивать или не убивать?” (Varlamov, электронный ресурс). Так, бывший директор школы Илья Петрович, отказываясь от служения науке и демократии, все свои упования возлагает на Бухару: „Не в Бога он уверовал, но душа его послушания возжаждала - самого темного и нелепого, но чтобы не ведать больше сомнения, найти наставника и внимать ему беспрекословно" (Varlamov, электронный ресурс). Однако не осуществились ожидания Ильи Петровича (и скульптора Колдаева): оказалось, что Бухарой и „Церковью Последнего Завета” управляют лжепророки. Наставник религиозной общины Вассиан, ученый и атеист, не верит в Бога, а бывший насильник Люппо - основатель секты скопцов - мстит всем за свое собственное физическое увечье. Разоблачение и петербургской секты, и старообрядческой общины в Бухаре приводит к десакрализации пространства. Более того, заданные как антиподы в начале повествования топосы Бухары 
и Петербурга в ходе развития сюжета становятся тождественными друг другу, обнаруживая свою „единосущную природу” (Myl'nikova, электронный ресурс). Мотив двойничества можно проследить в образах лжестарца Вассиана и Божественного Искупителя Люппо, Бухары и таинственного града Китежа, а в более широком контексте - сектантства и православия.

Символичен и финал произведения, завершающий мотив апокалипсиса: огонь, в котором сгорают старообрядцы, устраивая самосожжение, можно воспринимать как кару, очищающую мир от ереси, греха, пороков. Само место, где много веков существовала Бухара (царство несвободы и насильственного счастья), вдруг уходит под землю: „[...] однажды в вечерних летних сумерках поляна тихо колыхнулась, будто снялась с якоря, и погрузилась в болотную трясину" (Varlamov, электронный ресурс).

Особую смысловую нагрузку несет и образ ребенка, а точнее детей, рожденных от Ильи Петровича и являющихся, как можно предполагать, символом новой жизни, новой России. Отпуская детей в неизведанный мир, главный герой учит их единственной заповеди - любви:

Он сказал, что научил их самому главному - любить друг друга. Как бы ни было им тяжело, они должны держаться вместе и должны победить этот мир и спасти его. Он говорил о том, что в мире много людей, которые не любят других и хотят отнять у них свободу, отнятую у самих себя, но им, рожденным свободными, нечего бояться (Varlamov, электронный ресурс).

Подводя итоги сказанному выше, необходимо заметить, что анализируемый роман позволяет глубоко осмыслить общественные процессы кризисной эпохи, влияющие на одинокое и нуждающееся в поиске жизненных ориентиров сознание героя-интеллигента, судьба и духовный мир которого воплощали все противоречия человека эпохи рубежа веков. Герой-интеллигент Варламова - „новый лишний” - рефлексирует о своем месте в жизни, он постоянно чего-то ищет, сам иногда не понимая, что хочет найти, но это что-то настоящее, чистое, труднодостижимое. Следует добавить, что „новый лишний” герой Варламова, приобретая новые черты, проходя некую трансформацию, не утрачивает связи с ,лишним человеком” предыдущих эпох. Как замечает исследовательница Вера Расторгуева, „кризис современного мира требует новой правды о человеке, постичь которую современная проза пытается через диалог с классикой. В этом смысле герой того времени - литературный ориентир для постижения человека в сегодняшнем мире" (Rastorgueva, электронный ресурс). Герой-интеллигент перестроечного времени лишен опоры, не верит в советские ценности, а других не знает, лишь пытается нащупать их. Исследуемое произведение как своеобразный роман-предупреждение обладает сложным философским подтекстом, затраги- 
вающим вопросы веры, безверия, свободы личности и стремления человека к духовному совершенствованию. Несмотря на то, что герой Варламова слаб и беззащитен, именно такие „лишние” (в кавычках) люди как раз более всего и необходимы жизни. Этот „новый лишний”, как замечает Курбатов, „если устоит перед нешуточно вставшим на пороге Апокалипсисом, то устоит Любовью, Пониманием и Состраданием" (Kurbatov 7).

\section{Библиография}

Bahtin, Mihail. Voprosy literatury i èstetiki: Issledovaniâ raznyh let. Moskva, Hudožestvennaâ literatura, 1975.

Fedorova, Tat'âna. Poètika prozy A. Varlamova. Avtoreferat dissertacii na soiskanie učenoj stepeni kandidata filologičeskih nauk. Web. 27.04.2019. http://libweb.kpfu.ru/referat/2012/0-795233.pdf.

Kurbatov, Valentin. „Otraženie nebesnoj bitvy. Zametki na polâh knig Alekseâ Varlamova”. Literaturnaâ Rossiâ, 45, 2000, s. 3-7.

Lihačev, Dmitrij. „O russkoj intelligencii: pis'mo v redakciû”. Novyj mir, 2, 1993, s. 3-9.

Lotman, Ûrij. „Intelligenciâ i svoboda (k analizu intelligentskogo diskursa)”. Russkaâ intelligenciâ i zapadnyj intellektualizm: Istoriâ i tipologiâ. Red. Nikita Ohotin. Moskva, Ob"edinënnoe gumanitarnoe izdatel'stvo, 1999, s. 122-149.

Lunkin, Roman. „Novye religioznye dviženiâ v Rossii: hristianstvo i posthristianstvo v zerkalenovyh bogov i prorokov". Dvadcat' let religioznoj svobody v Rossii. Red. Aleksej Malašenko, Sergej Filatov. Web. 19.03.2020. https://carnegieendowment.org/files/1253120Years_text1.pdf.

Mineralov, Ûrij. Istoriâ russkoj literatury: 90-e gody XX veka: učeb. posobie dlâ stud. vysš. učeb. zavedenij. Moskva, Gumanitarnyj izdatel'skij centr Vlados, 2004.

Myl'nikova, Nadežda. Motiv dvojničestva v romane A. Varlamova „Zatonuvšij kovčeg”. Web. 24.07.2019. https://elibrary.ru/item.asp?id=26729844.

Nefagina, Galina. Russkaâ proza konca XX veka. Moskwa, Flinta, 2005.

Przebinda, Grzegorz. „Między ołtarzem a tronem. Cerkiew w Rosji po roku 1991”. Znak, 10, 2005, s. $25-37$.

Rastorgueva, Vera. „Geroj našego vremeni v sovremennoj proze”. Filologičeskij klass, 1, 2009. Web. 19.03.2020. https://filclass.ru/archive/2009/21/geroj-nashego-vremeni-v-sovremennoj-proze.

Remizova, Mariâ. „Vzvešen na vesah i najden legkim”. Nezavisimaâ gazeta, 114, 1999, s. 15-18.

Sčastlivceva, Ûlia. Proza Alekseâ Varlamova 1980-1990 gg.: žanrovo-stilevoe svoeobrazie. Avtoreferat dissertacii na soiskanie učenoj stepeni kandidata filologičeskih nauk. Web. 12.07.2019. https://new-disser.ru/_avtoreferats/01003320117.pdf.

Slaveckij, Vladimir. „Èlizium tenej”. Novyj mir, 11, 1997, s. 110-118.

Sokolov, Arkadij. Intelligenty i intellektualy v rossijskoj istorii. Sankt-Peterburg, Izdatel'stvo Sankt-Peterburgskogo gumanitarnogo universiteta, 2007.

Varlamov, Aleksej. „O dne že tom i čase nikto ne znaet. Apokaliptičeskie motivy v russkoj proze konca XX veka". Literaturnaâ učeba, 5/6, 1997, s. 69-77.

Varlamov, Aleksej. Zatonuvšij kovčeg. 2017. Web. 15.06.2019. https://azbyka.ru/fiction/zatonuvshij-kovcheg-aleksej-varlamov/.

Zinov'eva, Anna. Problema Drugogo v filosofii M. Bahtina. Web. 01.06.2019. https://cyberleninka. ru/article/n/problema-drugogo-v-filosofii-m-m-bahtina. 